\title{
Company profile: BioAscent Discovery Limited
}

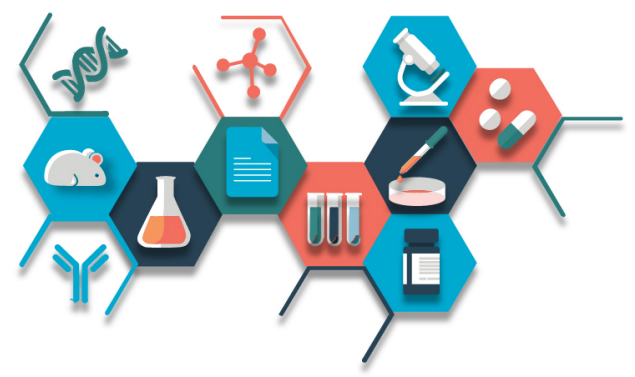

\author{
Mike Piper*,1, Sylviane Boucharens ${ }^{1} \&$ Philip Jones ${ }^{1}$ \\ ${ }^{1}$ BioAscent, Bo'Ness Rd, Chapelhall, Motherwell, ML1 5SH, UK \\ *Author for correspondence: mpiper@bioascent.com
}

First draft submitted: 4 February 2020; Accepted for publication: 5 February 2020; Published online: 13 March 2020

\section{What BioAscent do}

Founded in 2013, BioAscent is a leading provider of integrated drug discovery services, based at the former Organon and MSD Pharma R\&D site in Newhouse (Scotland, UK).

Their drug discovery services include de novo assay development, target analysis and bespoke screening strategies, compound screening, medicinal and synthetic chemistry, computational chemistry and compound management, all with access to a library of 125,000 lead-like compounds via Compound Cloud [1].

\section{Where BioAscent started}

The ability to recognize and act upon opportunities is woven into BioAscent's DNA. Back in 2012, MSD left the Newhouse site and BioCity Glasgow repurposed it as a scientific incubator. A new, $\$ 20$ million robotic compound management system and storage facility was included with the facilities which would have been lost had BioCity Glasgow not stepped in. In February 2013, BioAscent was founded, seizing the opportunity to make use of part of this facility and of the talented pool of scientists that had worked at the site.

From the start of our journey, our ardent determination to maximize our customers' drug discovery success has been a central driving force behind everything we do.

Initially, the company's main focus was on compound management and logistics and BioAscent now manages over one million compounds, delivering more than 90,000 screening plates worldwide. In their first year, they were selected as the compound logistics 'center of excellence' for the IMI European Lead Factory and began managing its extensive 500,000 compound Joint European Compound collection.

In 2016, BioAscent launched the Compound Cloud, a unique on-demand service providing a cost-effective and rapid online access to a diverse collection of IP-free, high quality compounds in screen-ready formats [1]. This revolutionary service enables chemists to preselect structures to fit their exact needs and avoid compounds with undesirable characteristics; thus, significantly reducing the likelihood of initial hits being rejected later on.

BioAscent's state-of-the-art facility allows them to provide a comprehensive outsourced compound management service for a large number of customers, with a focus on biotechs and virtual biotechs, where they can give access to pharma grade management facilities and expertise in a cost-effective manner. They are responsible for the storage, plating, distribution, logistics and tracking of compounds, supplying assay-ready plates as and when they are required. Through forming these collaborative alliances with partners, BioAscent quickly established its position as one of the largest and most efficient outsourced sample management providers in the world.

\section{Service expansion: integrated drug discovery}

In 2018, BioAscent implemented its strategic plan of combining integrated drug discovery and compound management into one facility - a significant step in BioAscent's journey made possible with the funding injection from Maven Capital Partners (London, UK) [2].

This led to the formation of the chemistry and bioscience teams, bringing many of the chemists and biologists from Merck's (NJ, USA) former facility into BioAscent. Furthermore, BioAscent was able to add the experienced management team from the European Screening Centre - also based onsite - into the company [3].

Now, as a fully integrated drug discovery CRO, BioAscent gets involved early in the drug discovery process, allowing the team to influence projects from start to finish, ensuring the right decisions are made to maximize 
the chances of success. This is in addition to their well-established, stand-alone chemistry, biology and compound management services. It is this specific combined offering of services that sets BioAscent apart, even from their well-established and international competitors.

The combination of these capabilities, along with the team's reputation and expertise, has resulted in an enviable customer base of biotechs, virtuals, VC-funded academic spinouts and academic groups. In addition, BioAscent won a second 5-year contract with the European Lead Factory an IMI2 initiative earlier this year, chosen as one of 20 partners in seven countries to deliver support to its ESCulab project, which aims to push forward the transformation of potential drug targets to new medicines. BioAscent was also selected to deliver services to customers of UK Medicines Discovery Catapult's Virtual R\&D Discovery Services platform.

\section{A growing team}

BioAscent's growth follows a major restructure led by CEO, Paul Smith, to assemble a world-class team and includes personnel from the former MSD site: Phil Jones (CSO with over 30 years medicinal chemistry and drug discovery experience) and Sylviane Boucharens (COO and co-founder, and former head of global compound repository and in vitro screening at $\mathrm{MSD}$ ). Sylviane spearheaded BioAscent's successful expansion to becoming a fully integrated drug discovery CRO and she was included in the BioBeat 2018 list of 50 Movers and Shakers in BioBusiness as a result of this success. Angus Morrison (Director of Chemistry) and Stuart McElroy (Director of Biosciences) joined the management team in 2018 to oversee the development and delivery of this new service offering. Under Angus and Stuart's leadership, our biosciences and medicinal chemistry teams offer world-class expertise and a proven ability to deliver.

The commercial side of the business is equally strong with chartered accountant and experienced finance director, Ian McDonald (CFO) and Mike Piper (CCO), who has a track record in sales and marketing strategy, general management, licensing and contract negotiation.

BioAscent has also expanded its team of highly skilled scientists, growing from seven members of staff in January 2018 to 40 in December 2019, supporting the retention of valuable skills and expertise in the region, as well as attracting new talent into the area.

They continue to have ambitious growth plans and have recently entered the US market in order to support the rising demand for integrated drug discovery services overseas, a trend that is expected to continue. Julian Abery was appointed as Director of Business Development, North America, bringing a wealth of knowledge and experience in the US-based pharma and biotechnology research market.

\section{'Real world' impact}

BioAscent works with customers across the globe to help influence and improve success in drug discovery projects. Their customers are typically looking for an expert, advisory partner CRO with a consultative approach. Drawing on their knowledge and expertise, BioAscent are able to challenge and advise on doing things in the best way for the benefit of the project - one of the reasons customers turn to BioAscent.

Financial \& competing interests disclosure

All authors are employees of BioAscent. The authors have no other relevant affiliations or financial involvement with any organization or entity with a financial interest in or financial conflict with the subject matter or materials discussed in the manuscript apart from those disclosed.

No writing assistance was utilized in the production of this manuscript.

\section{Open access}

This work is licensed under the Attribution-NonCommercial-NoDerivatives 4.0 Unported License. To view a copy of this license, visit http://creativecommons.org/licenses/by-nc-nd/4.0/

\section{References}

1 BioAscent. Compound Cloud (2020). https://compoundcloud.bioascent.com/

2 BioAscent. BioAscent secures investment to expand its integrated drug discovery services (2018). www.bioascent.com/news-events/news/bioascent-secures-investment-to-expand-its-integrated-drug-discovery-services

3 European Lead Factory. European Screening Centre (2020). www.europeanleadfactory.eu/about/assets/european-screening-centre 